\title{
Active Vibration Suppression of Aerobatic Aircraft Wing by Acceleration Feedback Controller
}

\author{
Ahmed A. Ali, Ph.D. \\ Asst. Prof. \\ Baghdad University- \\ Engineering College
}

\author{
Mahmood Wael Saeed \\ Ph.D. Student \\ Applied Mechanics \\ Baghdad University \\ Mechanical Engineering
}

\begin{abstract}
Vibration of some structures might be accepted under restricted limits depending on their design, application and many other factors. Aircraft wing is a structure need to be stable as possible, but there are many disturbances act on wing, so using of active vibration control for vibrated wing can serve to eliminate or suppress the major amount of wing oscillation. In the present work, direct acceleration feedback method is utilized to be used as a controlling technique to satisfy wing stability. Numerical model was simulated in ANSYS environment where the controlling method was totally integrated to generate necessary actuation voltage to derive piezoelectric actuators based on acceleration feedback. Six piezoelectric transducers were modeled in ANSYS by using element SOLID5. Experimental part includes manufacturing (1:6) scaled aircraft wing with two boxes inside and equipped with six piezoelectric transducers worked as sensor/actuator besides labview software inside which the controlling loop was integrated. Modal analysis was performed for numerically simulated model and includes the first six modes of vibration. Free and controlled responses of the tested wing were presented for numerical and experimental model. Results show high degree of agreement between experimental and numerical models. Results show that utilizing the acceleration feedback method for active vibration controlling method can suppress wing vibration and that will pave the way for further application of this controlling method.
\end{abstract}

\section{General Terms}

Active Vibration Control

\section{Keywords}

Aircraft wing, Direct acceleration feedback, Finite element, Piezoelectric transducers, Modal analysis, Active vibration control.

\section{INTRODUCTION}

To reduce the amplitude of vibrating structures, two types of controlling strategies are possible; first one by using dampers or shock absorbers; the vibration amplitude can be reduced, in a short span of time. By using the layers of viscoelastic materials, the same effect can be satisfied. Composite materials made by sandwiching the layers of viscoelastic materials between the layers of parent material, are quite common. Reducing the vibration amplitude by this technique is called Passive control [1].The second strategy of controlling methods is obtained by using the structure mounted with smart materials. Due to the vibrations, the strain is developed in smart sensors fixed on the surface of the structure. This strain produces electrical voltage in these materials. This voltage is used as sensed signal. Using the information of the sensor voltage, suitable feedback electrical voltage is applied to the actuators made of smart materials. The applied actuator voltage produces strain in opposite direction and reduces the vibration amplitude. This type of vibration control is called Active Control (AC). An active control system uses some external adjustable or active (for example, electronic) device, called an actuator, to provide a means of shaping or controlling the response. Passive control, on the other hand, depends only on a fixed (passive) change in the physical parameters of the structure. Active control often depends on current measurements of the response of the system, and passive control does not. Active control requires an external energy source, and passive control typically does not [1]. The present work deals with active vibration control of an idealized cantilever composite wing box element by using acceleration feedback method. The structure considered is essentially a shell, which contains a tapered two box sections. Based on literature review piezoelectric transducers (PZT) were widely used as actuators/sensor in many applications related to active vibration suppression. Analyzing of the cantilever smart plate using Finite Element Method (FEM) was presented in many studies besides examining the natural frequency values for the cantilever plate with and without piezoelectric patch, then simulating the natural frequency of the smart plate by (ANSYS) program to verify the system. Mathematical model using MATLAB program were the most famous followed strategy that was noticed with literature. Author in [2] presented a finite element formulation to model the dynamic as well as static response of laminated composite plates containing integrated piezoelectric sensors and actuators subjected to both mechanical and electrical loadings. The formulation is based on the classical laminated plate theory and Hamilton's Principle. Several numerical examples are presented. Smart plate consists of a rectangular aluminum plate was modeled in a cantilever configuration with surface bonded by piezoelectric patches in reference [3], where the study used ANSYS software to derive the finite element model of the smart plate; and studied the influences of the actuator placement and size on the response of the smart plate [3]. Authors in [4] focused on some recent developments in modeling and numerical analysis of piezoelectric material systems and controlled smart structures based on a general purpose finite element software with the possibilities of static and dynamic analyses and simulation. Design and simulation of controlled smart structure is also presented, using a statespace model of a structure obtained through the finite element analysis as a starting point for the controller design. For the purpose of the control design for the vibration suppression discrete-time control design tools were used, such as optimal Linear Quadratic (LQ) controller incorporated in a tracking system. In reference [5] a numerical modeling of a plate structure containing bonded piezoelectric material was presented. A numerical model is developed based on 
Kirchhoff's plate theory. A computational program is implemented for analyzing the static and dynamic behavior of composite plates with piezoelectric layers symmetrically bonded to the top and bottom surfaces. Reference [6] presented modeling and vibration control of thin plates taking into account defects. The classical plate theory is used for the finite element model. The defects are modeled by equivalent change of the elastic modulus of the corresponding element. Active Linear Quadratic Regulator (LQR) and Linear Quadratic Gaussian (LQG)/H2 control design are implemented for the plates supplied with sensors and actuators. The influence of the placement of the defects and of the control forces on the vibration controlling was investigated. Authors in reference [7] studied a higher order finite layer formulation based on the Auxiliary Nodal Surface (ANS) technique for a free vibration analysis of rectangular plates. The free vibration analysis has been performed using the generalized Jacobi iteration method, thus finding the natural frequencies and modes of vibration. Team of reference [8] worked on achieving the active vibration control of a flexible structures using piezoelectric material. A simply supported plate structure, which is supported at two opposite ends, is taken as the flexible structure with piezoelectric materials as sensors and actuators. The active controller was designed to control first three modes of vibration of plate. Further a LQR controller is applied for attenuating the global structural vibration. The model designed for study was duly verified with the results from past literature and an agreement between the both was observed. Authors in [9] acted modeling and design of a pole placement and output feedback control for a smart flexible cantilever beam for Single-Input-SingleOutput (SISO) case. Feedback sensing and actuation actions were done by using patches of piezoelectric layer, it is bonded to the master structure as sensor/actuator at a certain position of the cantilever beam. The smart structure is modeled based on the concept of piezoelectric theory, Bernoulli-Euler beam theory, using state space techniques and (FEM). The number of modes is reduced using the controllability and observability grammians retaining the first three dominant vibratory modes, and for the reduced system, a control law is designed using pole placement and output feedback techniques. Researchers in reference [10] performed the active vibration control of composite beam with included piezoelectric transducers. Actuators and sensors were modeled by FEM based on the third order theory. For computing the total charge in the sensor, the direct equation of piezoelectric is used and the actuator provided damping effect on the smart beam by coupling a negative velocity feedback control. The modal superposition technique and a new mark- $\beta$ method are used in the finite element analysis to obtain the dynamic response of smart beams. Algorithm is achieved using Matlab tool for calculating the different values of variables. Reference [11] displayed design and modeling of beam with Piezoelectric Ceramic (PZT Lead Zirconate Titanate) patches are attached on the bottom and top surface as actuator/sensor collocated couple. The Active Vibration Control (AVC) using PID (Proportional-Integral-Derivative) controller was examined in [11]. The smart beam is molded as Euler-Bernoulli beam as well as the two PZT patches are treated as Euler-Bernoulli beam. The effect of stiffness and mass of PZT patches in the design of smart structure as well is considered. The smart beam is modeled using FEM. The patches can be located near the free end, at middle or near the fixed end of the beam as collocated couple. The first two dominant vibratory modes are observed in the design. The effect of PZT actuator/sensor couple is studied at various locations of smart beam in control of vibration. The best result is obtained when the PZT actuator/sensor pair is located at the near of fixed end. The general outline steps of this work were to build up the wing with two internal boxes structure by using software (ANSYS V.15) with corresponding number of layers, orientation. Integration of acceleration feedback controlling technique was also performed to suppress wing's vibration for first mode. Manufacturing a composite wing with two inner boxes from (E-glass) was carried out to validate the simulation results. The structural model used in this work is in the form of a two boxes, fiber-reinforced composite wing box. The considered structure model is similar to that developed in reference [12].

\section{FINITE ELEMENT MODEL}

There are many practical engineering problems for which exact solution cannot be obtained. The inability to obtain an exact solution may be attributed to either the complex nature of governing differential equations or the difficulties that arise from dealing with the boundary and initial conditions. To deal with such problems, numerical approximation may be resorted. There are two common classes of numerical methods:

\section{Finite difference method.}

\section{Finite element method.}

\section{Boundary element method.}

Engineers routinely use the Finite Element Method (FEM) to solve everyday problems of stress, deformation, heat transfer, fluid flow, electromagnetic, etc. using commercial as well as special purpose computer codes; ANSYS is one of the most versatile and widely used of the commercial finite element programs. In this work a composite acrobatic aircraft wing with two boxes is excited manually by $(2 \mathrm{~mm})$ in its transverse direction and leaved to be oscillating freely. Based on acceleration feedback of wing's tip the controlling loop was operated to generate controlling voltage that will derive PZT patches. Figure (1) shows the FE model of composite acrobatic aircraft wing with two inner boxes. Inner construction of the mentioned wing was totally simulated also and presented in figure (2). Mechanical properties of the wing manufacturing material besides wing body configuration data are presented in tables (1-2) respectively [12]. The finite element method has developed simultaneously with the increasing use of high- speed electronic digital computers and with the growing emphasis on numerical methods for engineering analysis. Although the method was originally developed for structural analysis, the general nature of the theory on which it is based has also made possible its successful application for solutions of problems in other fields of structures by an assemblage of subdivisions called finite elements. These elements are considered inter connected at joints which are called nodes or nodal points [13]. Aircraft structure components are highly redundant and require some degree of simplification or idealization before they can be analyzed. A high degree of accuracy can only be obtained by using computer based techniques such as the finite element method. The finite element analysis will be used to obtain the displacement, stress, natural frequency and dynamic response as they are considered the main design parameters. The wing will be divided into elements for the isotropic shell structure the element, where (4-node quadrilateral element) had been used. The elements SHELL181 and SOLID5 are used for wing structure and PZT respectively as presented in table (3). Inner construction of composite two boxes airfoil is presented with its corresponding dimensions in figure (3). Based on modal analysis for tested wing a convergence test was performed to decide the best elements counts, which can serve 
to model the wing more precisely. The test shows that 22046 element can satisfy a relatively stable values of natural frequency for tested wing, where it was noticed that insignificant changing in the natural frequency was satisfied with further finning of wing's mesh. As mentioned previously SHELL181 was selected to mesh the whole wing structure where it is appropriate for analyzing thin to thick shell structure. It has translations in the $\mathrm{x}, \mathrm{y}$ and $\mathrm{z}$ directions and rotations about the $\mathrm{x}, \mathrm{y}$, and $\mathrm{z}$-axes therefor six degrees of freedom at each node and it is four node elements. SHELL181 is suitable for large rotation, linear and large strain nonlinear applications. Change in shell thicknesses are accounted for in nonlinear analyses [71]. SHELL181 is used for layered applications for modeling sandwich construction or composite shells. The first-order shear-deformation theory (usually referred to as Mindlin- eissner shell theory) is used for modeling composite shells in order to improve accuracy in modeling. The element formulation is based on logarithmic true stress and strain measures. While SOLID5 has a 3-D magnetic, thermal, piezoelectric, electric and structural field capability with limited coupling between the fields. The element has 8 nodes. Each node has $\mathrm{u}_{\mathrm{x}}, \mathrm{u}_{\mathrm{y}}$ and $\mathrm{u}_{\mathrm{z}}$ displacements along $\mathrm{x}, \mathrm{y}$, and $\mathrm{z}$ axis, with up to $6 \mathrm{DOF}$ at each node. Scalar potential formulations are available for modeling magneto static fields in a static analysis. When used in piezoelectric and structural analyses, SOLID5 has stress stiffening capabilities and large deflection. The prism shaped element is produced by defining duplicate node numbers. A prism shaped element is useful in modeling a system that has a geometric curvature. SOLID5 element is capable to modeling seven different types of specialties. When chosen this type of piezoelectric, Mechanical APDL will only consider the behaviors of the element for SOLID5 in $\mathrm{u}_{\mathrm{x}}, \mathrm{u}_{\mathrm{y}}, \mathrm{u}_{\mathrm{z}}$ and volt degrees of freedom. It shall be noted that $\mathrm{u}_{\mathrm{x}}, \mathrm{u}_{\mathrm{y}}$ and $\mathrm{u}_{\mathrm{z}}$ indicate the displacements in the global coordinate system $\mathrm{x}, \mathrm{y}$ and $\mathrm{z}$ directions, while volt mentioned the difference in potential energy of the electrical particles between two locations.

Generally piezoelectricity is considered a linear theory in which the piezoelectric, elastic, and dielectric coefficients are represent as constants [14]. Boundary condition of meshed wing is presented in figure (4).

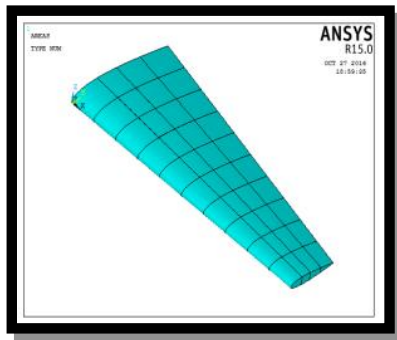

Fig. 1 Finite element model of tested wing.

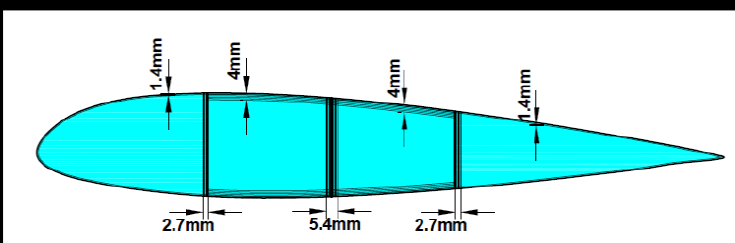

Figure (3-2) Composite wingbox

Fig .3 Inner construction of airfoil section NACA (23015)

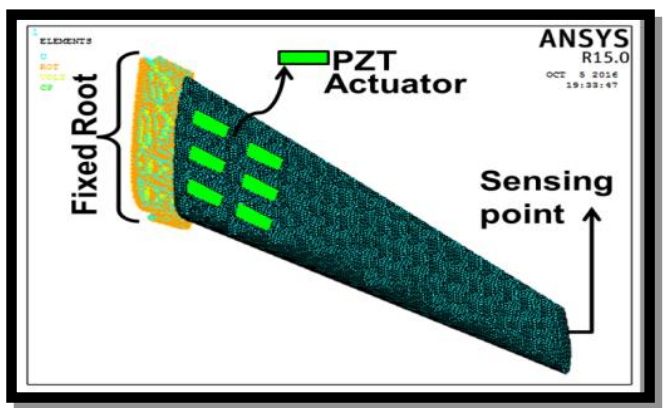

Fig. 4 Meshing and boundary condition of tested wing

Table (1) Mechanical Properties of Composite material

\begin{tabular}{|c|c|c|c|c|c|}
\hline Material & $\mathrm{E}_{\mathrm{x}}(\mathrm{Gpa})$ & $\mathrm{E}_{\mathrm{y}}(\mathrm{GPa})$ & $v_{\mathrm{xy}}$ & $v_{\mathrm{yz}}$ & $\mathrm{G}_{\mathrm{xy}}(\mathrm{GPa})$ \\
\hline $\begin{array}{c}\text { Woven } \\
\text { fiber }\end{array}$ & 38 & 38 & 0.2 & 0.05 & 5.3 \\
\hline
\end{tabular}

Table (2) Wing body configuration data

\begin{tabular}{|l|c|}
\hline Wing Span (m) & 4.6 \\
\hline Aspect ratio & 6.7 \\
\hline Taper ratio & 0.44 \\
\hline Root chord(m) & 2.03 \\
\hline Tip chord(m) & 0.8932 \\
\hline Wing root section profile & NACA 23015 \\
\hline Wing tip section profile & NACA 23012 \\
\hline Wing shape & Trapezoidal \\
\hline
\end{tabular}

Table (3) Elements types of FE wing model

\begin{tabular}{|c|c|}
\hline Part & $\begin{array}{c}\text { Element } \\
\text { Type }\end{array}$ \\
\hline Surface & SHELL 181 \\
\hline Ribs & SHELL 181 \\
\hline Spars & SHELL 181 \\
\hline $\begin{array}{c}\text { Piezoelectric } \\
\text { transducer }\end{array}$ & SOLID5 \\
\hline
\end{tabular}

\section{ANALYTICAL PRESENTATION}

For this model, active vibration control was achieved using Acceleration Feedback Control (AFC). The equations of motion of a system under AFC are as follows [15].

$[\mathrm{M}]\{\ddot{\mathrm{x}}\}+[\mathrm{C}]\{\dot{\mathrm{x}}\}+[\mathrm{K}]\{\mathrm{x}\}=f+\mathrm{Bu}$

where $\mathrm{M}, \mathrm{K}$ and $\mathrm{f}$ are the mass, stiffness and force matrices, respectively.

Eq. (1) also includes the control forces $u$ and the influence matrix B acting on the system. The structural damping is omitted to demonstrate the effect of the controller. Control force $\mathrm{u}$ is described as following:

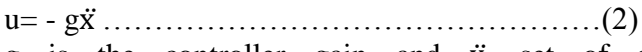

$\mathrm{g}$ is the controller gain and $\ddot{x}$ set of acceleration measurements.so by combination of both equations (1) and (2) will lead to:

$[\mathrm{M}]\{\ddot{\mathrm{x}}\}+[\mathrm{C}]\{\dot{\mathrm{x}}\}+[\mathrm{K}]\{\mathrm{x}\}=f-\mathrm{Bg} \ddot{\mathrm{x}}$

For this study, two values of the feedback gain $\mathrm{g}$ were tested which were $0.7 \& 1.7$. This value is motivated by three conditions. First, for acceleration feedback control stability. Second, the larger the gain, the larger the amount of reduction that can be attained. Finally, control scheme is needed to be feasible. This latest condition is due to the fact that the amount of control force that can be generated by the stack is limited. In order to implement the acceleration feedback controller it is important to read the acceleration value at the 
tip of the studied wing where the excitation was applied. But the first step was to apply an excitation on the wing's tip as impulse force, and leaving the wing vibrating freely.

At each time step tip's acceleration was fed to the controller circuit which is totally simulated in ANSYS environment. Final station for each feedback was generating the actuation voltage which is sent to the actuators for achieving the vibration suppression.

\section{CLOSED LOOP SIMULATION}

For Direct Acceleration Feedback (DAF) controlling, voltage was presented by $\left(V_{D A V}=\mathrm{a} \times g_{a f}\right)$, where $V_{D A V}$ is the actuation voltage, $a$ was the feedback wing's tip acceleration and $g_{a f}$ was the gain of (DAF) controller [16].

In ANSYS environment the displacement changing in $\mathrm{z}$ direction was extracted for each step by using [*get] command for tip node, then by using $d^{2} z / d t^{2}$ one can get $a_{z}$ which is the acceleration of tip point of the wing in $z$ direction, where $\mathrm{dz}$ is the difference between two extracted displacement in $\mathrm{z}$ direction within single time step, $\mathrm{dt}$ is the time step. Then the calculation of actuation voltage or in another word the damping voltage was calculated at each time step until the *do---*enddo for time was finished. Then the calculation process is repeated at each time step to estimate the required damping voltage that must be applied to PZT. In this work voltage limit of PZT was leveled up to $\pm 100 \mathrm{v}$, in order to prevent the actuation voltage be more than voltage limit of PZT. The damping matrix was calculated according to equation (4)

$$
\mathrm{C}=\alpha[\mathrm{M}]+\beta[\mathrm{K}]
$$

where $\mathrm{M}$ is the mass matrix, $\mathrm{K}$ is the mechanical stiffness matrix. In equation (5), $\alpha$ and $\beta$ are computed from

$\xi_{\mathrm{i}}=\frac{\alpha}{2 \mathrm{w}_{\mathrm{i}}}+\frac{\beta \mathrm{w}_{\mathrm{i}}}{2}$

where $\xi_{i}$ and $w_{i}$ are the damping ratio and circular natural frequency of the ith mode respectively $\alpha$ and $\beta$ are the Rayleigh coefficients.

\section{EXPERIMENTAL MODEL}

A model of carton paper was manufactured with a scale ratio (1:6) of the original prototype wing [17][18] which had been numerically analyzed by ANSYS. The dimensions of the prototype wing is given in table (1), which is regarded as the base in manufacturing the model after a reduction in size of (1:6).

\subsection{Steps for manufacturing the wing box model}

1-A two longitudinal boxes with same dimensions of the numerical model was prepared in laboratory as shown in figure (1), where they were manufactured from paper and covered with four layers of woven fiber; those two boxes are glued together with polyester to form the interior structure of the wing.

2- The second step was to cover the upper and lower surface of the boxes by the carton, the profile of the wing NACA 23015 and freshly mixed polyester is poured onto the woven fiber glass fabric (two layers over the surfaces) and is spread evenly throughout the fibers via brush, as illustrated in figure (5 point 1,2$)$.

3- The third step was to eliminate the un needed tips and redundancies from the edge of the wing model as shown in figure (5 point 3 ), after curing for about 24 hour the skin was covered with fiber glass to have a fine surface finish as shown in figure (5 point 4$)$.
4- The outer surface is polished with emery paper and then coating it with spray paint as shown in figure $(5$ point 5,6$)$.

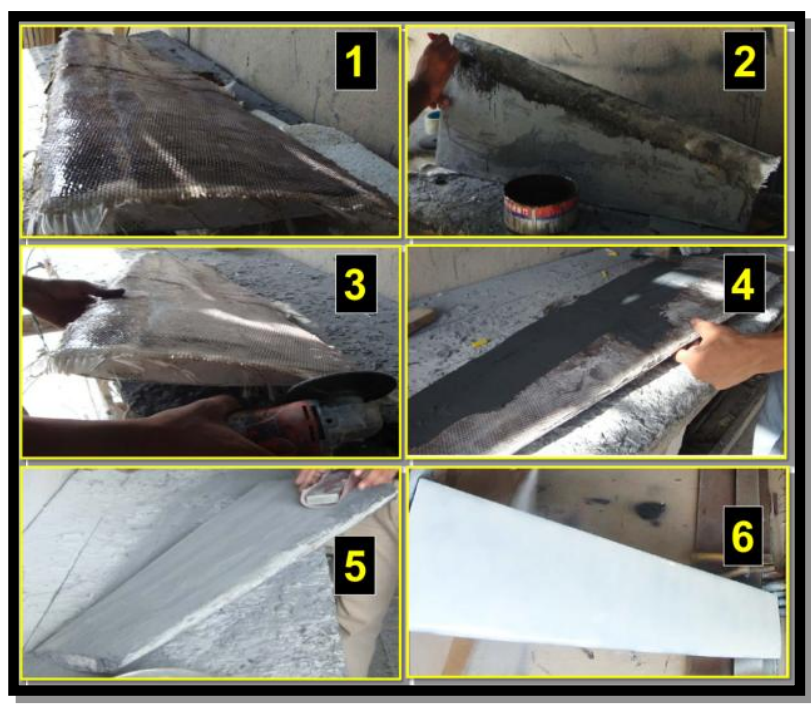

Fig. 5 Manufacturing steps of experimental model

\section{EXPERIMENTAL SETUP}

The test sample to be used in the experimental work is smart cantilever scaled wing. The experimental results will be compared with simulation results. A smart cantilever wing was made from composite material. Wing was equipped with single layer piezoelectric patches served as actuator and an accelerometer worked as a sensor. The piezoelectric actuators (PPA-1001-MIDE) are bonded onto wing's tip using special piezoelectric adhesive and PZT accelerometer 4344 sensor which is glued in the $\mathrm{z}$ direction of the lower surface of the wing. A schematic view of the experimental system is shown in figure (6). The smart cantilever wing is shown with experimental system in figure (7). In the experimental setup, multifunction analog output and analog input ((PCIe-6321)National Instrument) data acquisition are used for control action and data acquisition for the sensor and actuator. The accelerometer voltage (acceleration) data is fed to preamplifier and conditioner (2626 Breul \& Kjear- Charge amplifier) as presented in step(1) then to Shielded 68-Pin Connector block for DAQ Devices (SCB-68A-National Instrument). In step (2)this signal was sent to analog output and analog input ((PCIe-6321)-National Instrument). Steps (3) (4)are included; signal sending to controller loop in labview and transferring generated signal to analog output outlet respectively, the output actuator signals are simultaneously sent through the analog output card after a control actuator signal is calculated. In Step (5) the control actuator signals are sent to high voltage amplifier (HVPA) (Trek-2205) to drive the piezoelectric actuator. Driving of PZT actuators are satisfied in step 6. The input actuator signals to the (HVPA) are limited by $\pm 100 \mathrm{~V}$ due to the (PPA1001) voltage limit [19]. The tip displacements responses of the wing are obtained by calibration between the sensor voltages and tip displacements $U_{Z}$ where the curve is obtained for the responses, this curve is produced in a form of equation by using a curve fitting procedure with aid of LABVIEW software so that the displacement data are available in a high accuracy. Concurrence of multiple data acquisition is very important for sending the data and acquiring. Time step is $0.0001 \mathrm{~s}$ for the concurrence of data acquisition used in the closed loop control experiment. 


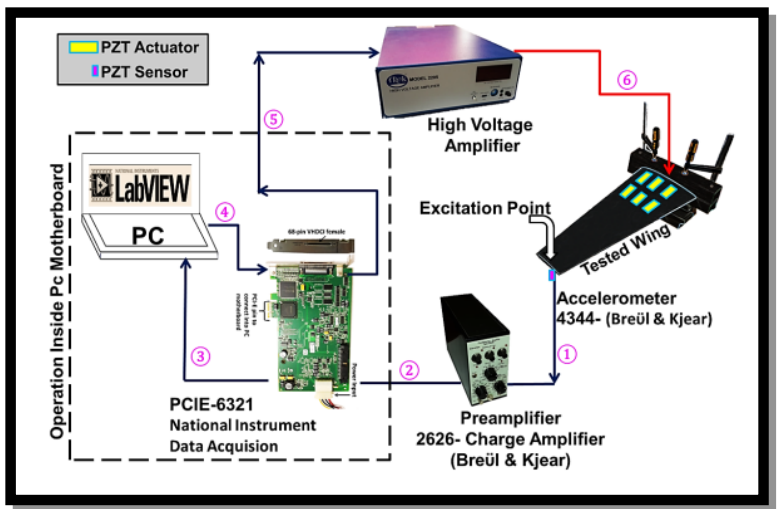

Fig. 6 Schematic presentation active vibration suppression Loop

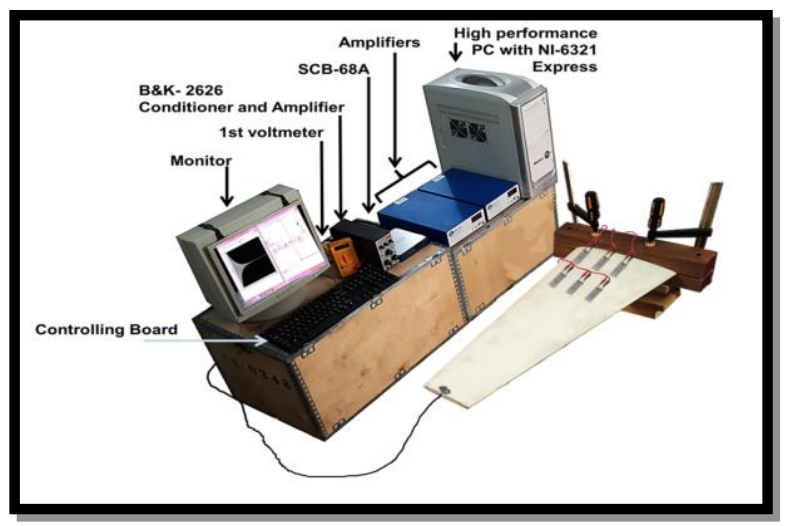

Fig. 7 Experimental testing setup

\section{RESULTS AND DISCUSSIONS}

In this section, the numerical results are presented and discussed for the dynamic behavior and active vibration control of smart wing subjected to suddenly applied impulse displacement of $2 \mathrm{~mm}$. It is to be note that the external load is applied for a very short period of time to set free vibrations in the structure. The time step size determines the accuracy of the solution: the smaller its value, the higher the accuracy. A time step which is too large may cause errors which can affect the overall response of the structure while a time step which is too small will waste computing resources. The standard rule to choose appropriate time step is to take approximately 20 points per cycle of the highest frequency of interest which results in a reasonable accurate solution. The time step considered in this study is $0.0001 \mathrm{Sec}$. Modal analysis was performed for tested wing and the first six modes of vibration were estimated with corresponding natural frequency and they were presented in figure (8) from a to $f$ in which natural frequencies with corresponding modes were presented for 6 modes respectively. It was noticed that the bending mode happened at first mode, so this mode was selected to be suppressed. Other modes are presented to give an indication of mode shape at each frequency for further future development of the current wok, where these modes can be targeted. Free and controlled responses are presented in figure (9), in which responses (displacement-time) were presented for numerical model of tested wing and in order to validate these responses experimental work was carried out. Responses were also measured experimentally and they are presented in figure (10). Acceptable agreement was noticed by comparison the settling time between those responses except some protrusions appear in experimentally recorded signals due to some white noises that accompanied measurement process.
This study reveals that the response acquired from the piezoelectric sensor corresponding to structural vibrations. The higher actuation force results in quick damping of the structural vibrations and reduces the settling time of undesired vibrations. From results it was noticed that about $20 \%$ of settling time was enhanced (reduced) when using acceleration feedback method with gain of 0.7 , while about $45 \%$ of oscillation time was enhanced with gain of 1.7. all comparisons percentage were presented by comparing with respect to corresponding free responses. In addition, it was very important to notice that experimentally measured responses validate the numerical one. The numerical results presented in this article are easily discernible and can be suitably used as a useful guideline for the evaluation of structural vibration attenuation performances with acceleration feedback controlling technique. As mentioned previously the gain selection was carried out to get better response, where it was noticed that the higher gain satisfy the best and faster response enhancement. But it is important to mention that the gain increasing was not opened process but it was followed according to actuators' voltage range, devices performance limit, displacement levels and corresponding excitation.

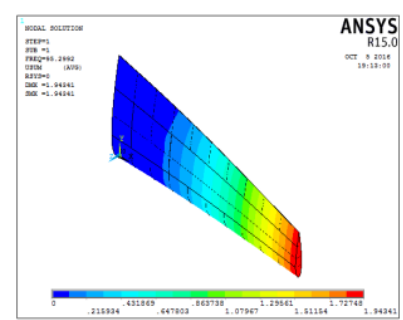

a. $1^{\text {st }}$ mode

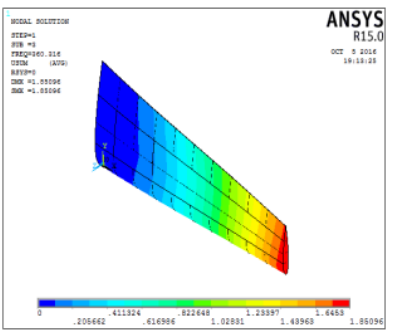

c. $3^{\text {rd }}$ mode

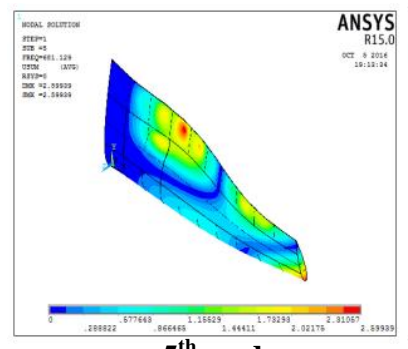

e. $5^{\text {th }}$ mode

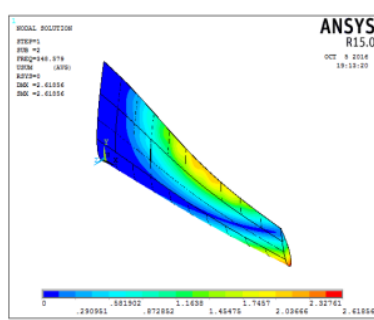

b. $2^{\text {nd }}$ mode

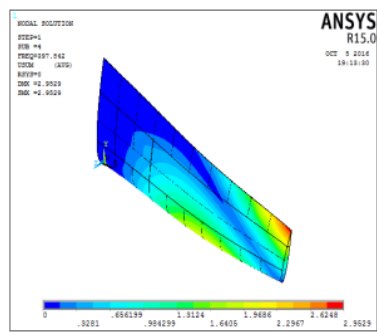

d. $4^{\text {th }}$ mode

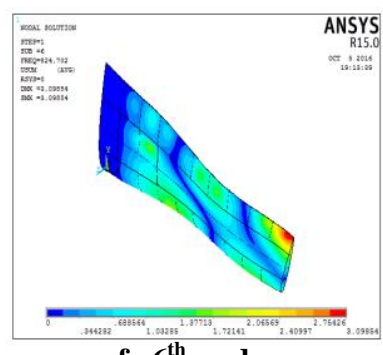

f. $6^{\text {th }}$ mode
Fig .8 Mode shape of Tested wing 


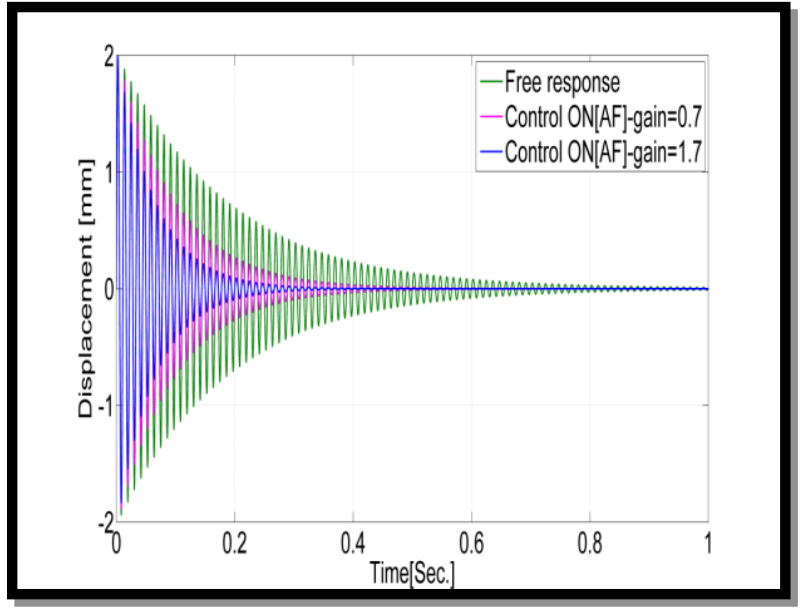

Fig. 9 Numerically measured response of simulated wing

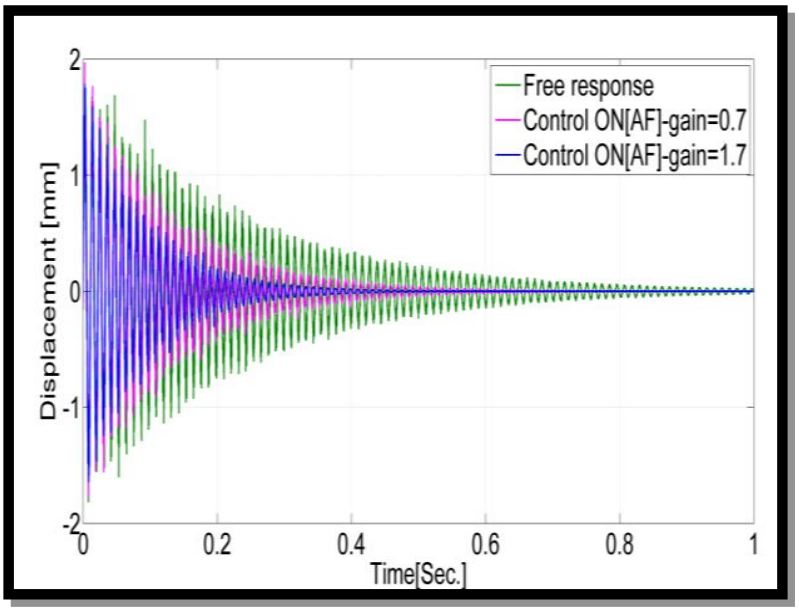

Fig. 10 Experimentally measured response of wing

\section{CONCLUSIONS}

Integrating control methods into the finite element models using commercial finite element programs enables to make the analysis of active control problems easier. The advantage of the technique does not require any mathematical model of the structure to design a controller. Some ANSYS (macros) that are combined with finite element solutions are developed to design a proper controller. Simulations are performed for the control of forced vibrations under a step input. It was noticed that using of acceleration feedback controller can suppress wing's vibration effectively with high performance. Experiments are conducted to verify the results obtained with the DAF control. It is observed that the experimental and closed loop simulation results are in well agreement. The present work shows that active control of piezoelectric laminated smart structures is successfully achieved by the DAF technique. Different composite materials in modern engineering structures with complicated geometries under various loading conditions can be studied in the future.

\section{REFERENCES}

[1] Daniel J. Inman," Vibration with Control",John Wiley \& Sons Ltd, the Atrium, Southern Gate, Chichester, West Sussex Po19 8sq, England, 2006.

[2] G. R. Liu, X. Q. Peng and K. Y. Lam, "Vibration Control Simulation Of Laminated Composite Plates With
Integrated Piezoelectrics", Journal of sound and vibration, 827-846 220 (5), 1999.

[3] YavuzYaman, TarkanCaliskan Et Al, "Active Vibration Control of a Smart Plate",Icas, 2002.

[4] Ulrich Gabbert1, Tamara NestorovićTrajkov, "Modelling, Control and Simulation of Piezoelectric Smart Structures Using Finite Element Method and Optimal LQ Control",Facta universities series: mechanics, automatic control and robotics vol.3, no 12, pp. 417 - 430, 2002.

[5] G. L. C. M. De Abreu, J. F. Ribeiro and V. Steffen, Jr., "Finite Element Modeling of a Plate With Localized Piezoelectric Sensors and Actuators", Universidade Federal De Uberlândia - Femec C.P. 593, 2004.

[6] Daniela G. Marinova, Georgios E. Stavroulakis Et Al, "Active Optimal Control of Damaged Smart Plates in Bending ", 6th European Solid Mechanics Conference28 August - 1 September, 2006.

[7] A.Abdul-Razzakand J. H. Haido, " Free Vibration Analysis of Rectangular Plates Using Higher Order Finite Layer Method", al-Rafidain Engineering Vol.15, No.3 2007.

[8] KapilNarwal, Deepak Chhabra, "Analysis of Simple Supported Plate for Active Vibration Control with Piezoelectric Sensors and Actuators", Journal of mechanical and civil EngineeringIssn: 2278-1684 Volume 1, Issue 1,Pp 26-39 May-June, 2012.

[9] Wedad Ibraheem Majeed, Shibly Ahmed Al-Samarraie, and Mohanad Mufaq, "Vibration Control Analysis of a Smart Flexible Cantilever Beam Using Smart Material", Journal of Engineering, Volume 19 January 2013.

[10] Pratik K. Gandhi, and J. R. Mevada, " A Finite Element Model and Active Vibration Control of Composite Beams with Distributed Piezoelectrics Using Third Order Theory", Department of Mechanical \& Mechatronics Engineering, Ganpat University, Kherva, International Journal of Engineering Research and Applications (IJERA) ISSN: 2248-9622 Vol. 3, Issue 3, May-Jun 2013, pp.940-945.

[11] Saurabh Kumar, Rajeev Srivastava, and R.K.Srivastava, " Active Vibration Control of Smart Piezo Cantilever Beam Using PID Controller", International Journal of Research in Engineering and Technology eISSN: 23191163 | pISSN: 2321-7308, Volume: 03 Issue: 01 | Jan2014.

[12] Ahmed A. Ali, Azhar K. Farhood,"The Static Analysis of Composite Aircraft Wing-Box Structure", Journal of Engineering, Volume 17, Number 6, 2011.

[13] Harily, G. "Fundamentals of the finite element method",Mac Millan pubishing Co, 1986.

[14] ANSYS user manual (version 10.0). USA: ANSYS, Inc. <www.ansys.com>

[15]Shirley Jane Dyke,1996, " Acceleration Feedback Control Strategies for Active and Semi-Active Control Systems: Modeling, Algorithm Development, and Experimental Verification" (doctoral dissertation ), Retrieved from Department of Civil Engineering and Geological Sciences Notre Dame, Indiana. 
[16] Maxime P. Bayon de Noyer, Patrick J. Roberts, Sathya V. Hanagud, Georgia Institute of Technology, School of Aerospace Engineering, Atlanta, Georgia 30332-0150, The American society of Mechanical engineers(ASME), 1999.

[17] Dimensions sheet of NACA23015, Available from: http://airfoiltools.com/airfoil/details?airfoil=naca23015-il

[18] Dimensions sheet of NACA23012, Available from: http://airfoiltools.com/airfoil/details?airfoil=naca23012-il

[19] PPA-1001 Data sheet, MIDE Co. Ltd.,PPA-series 2016. 